03

\title{
Прыжковая проводимость в поликристаллах EuS
}

\author{
(C) М.М. Казанин, В.В. Каминский , М.В. Романова, Н.Н. Степанов, А.В. Голубков, Н.В. Шаренкова \\ Физико-технический институт им. А.Ф. Иофрфе РАН, \\ Санкт-Петербург, Россия \\ ๑ E-mail: vladimir.kaminski@mail.ioffe.ru
}

(Поступила в Редакцию 28 апреля 2016 г.)

Проведены исследования электропроводности поликристаллов моносульфида европия (EuS) в зависимости от температуры в диапазоне $150-400 \mathrm{~K}$ и давления до $620 \mathrm{MPa}$. Показано, что электроперенос осуществляется главным образом за счет прыжкового механизма.

Работа выполнена при поддержке РФФИ (грант № 14-08-00591А).

Электрические свойства объемных поликристаллических образцов $\mathrm{EuS}$ при комнатных и более низких температурах ранее исследовались мало. Это связано с трудностью технологии приготовления (высокие температуры и наличие легкоокисляющегося компонента) и измерений из-за высокого удельного электросопротивления. Имеются лишь ранние данные, изложенные в работе [1], где проводились измерения электропроводности в температурном интервале $550-1500 \mathrm{~K}$, данные, полученные при $T<80 \mathrm{~K}$ в магнитном поле [2], а также результаты исследований при высоких давлениях [3]. Кроме того, имеются данные об электрических свойствах тонких поликристаллических пленок $\mathrm{EuS}$, полученные в [4]. В последнее время возник интерес к исследованию электрических свойств $\mathrm{EuS}$ в связи с созданием гетероструктур $\mathrm{SmS} / \mathrm{EuS}$, которые нашли применение при исследовании термовольтаического эффекта и возможности преобразования тепловой энергии в электрическую на его основе $[5,6]$. В настоящей работе рассмотрен механизм электропереноса в поликристаллах $\mathrm{EuS}$ в интервале температур 150-400 K, поскольку он наиболее интересен для исследования термовольтаического эффекта и ранее не изучался.

Исследованные поликристаллические образцы $\mathrm{EuS}$ были изготовлены методом синтеза из простых веществ (европия и серы) [1] с последующим прессованием полученных порошков и отжигом при $T=1600-1900^{\circ} \mathrm{C}$. Согласно данным рентгеноструктурного анализа, полученные образцы имели структуру типа $\mathrm{NaCl}$ с постоянной кристаллической решетки 5.96-5.97 А и характерными размерами областей когерентного рассеяния рентгеновского излучения 450-600 А.

При паспортизации образцов электросопротивление измерялось двух- и четырехзондовым методами, концентрация электронов проводимости и их подвижность рассчитывались на основе измерений эффекта Холла. Температурная зависимость электропроводности поликристаллических образцов $\mathrm{EuS}$ исследовалась на пластинах размером $5 \times 2 \times 0.5 \mathrm{~mm}$, полученных шлифованием исходных слитков. Расстояния между нанесенными на одну из поверхностей образца Al- или Ag-контактами составляли 50 или $100 \mu \mathrm{m}$. Их нанесение осуществлялось методом резистивного напыления в вакууме. Из-за низкой величины электропроводности для измерений использовался двухконтактный метод. Измерения в температурном интервале $\sim 160-400 \mathrm{~K}$ проводились в вакуумированном (до $10^{-2} \mathrm{~Pa}$ ) и снабженном нагревателем термостате по следующей схеме: измерялось падение напряжения на образцовом сопротивлении, соединенном последовательно как с образцом, так и с источником питания постоянного тока. Регистрация падения напряжения на образцовом сопротивлении и образце проводилась при помощи электрометра ЭМ-1 и вольтметра Щ1518. Электросопротивление $\mathrm{EuS}$ при высоких давлениях измерялось в клапанной камере в среде полиэтилсилоксановой жидкости ПЭС-5 двухзондовым методом на постоянном токе и непосредственно омметром E6-10. Оба метода показали совпадающие результаты. Образцы для исследований вырезались из различных частей исходного поликристаллического слитка $\mathrm{EuS}$ и имели примерно одинаковые размеры $\sim 2 \times 2 \times 1 \mathrm{~mm}$.

Были исследованы электрические параметры нескольких десятков поликристаллических образцов EuS. При $T=300 \mathrm{~K}$ были получены следующие значения: для удельного электросопротивления $\rho=10-10^{7} \Omega \cdot \mathrm{cm}$, для концентрации электронов проводимости $n=10^{14}-10^{17} \mathrm{~cm}^{-3}$, для подвижности носителей заряда $\mu=0.2-6 \mathrm{~cm}^{2} / \mathrm{V} \cdot \mathrm{s}$. Такой большой разброс параметров может быть объяснен наличием комбинированного (включающего прыжковый и зонный) механизма электропереноса, как было показано нами для тонких поликристаллических пленок $\mathrm{EuS}$ в [4]. При этом относительный вклад обоих механизмов в разных образцах мог быть различен.

Для проверки выдвинутого предположения была измерена температурная зависимость электропроводности $\sigma$ поликристалла EuS. Как известно [7], при наличии прыжковой проводимости и довольно низких температурах электропроводность полупроводников подчиняется закону Мотта

$$
\sigma=\sigma_{0} \exp \left[-\left(\frac{T_{0}}{T}\right)^{1 / 4}\right]
$$

где $\sigma_{0}$ и $T_{0}-$ характеристические для данного образца параметры, не зависящие от $T$. Представленные на рис. 1 


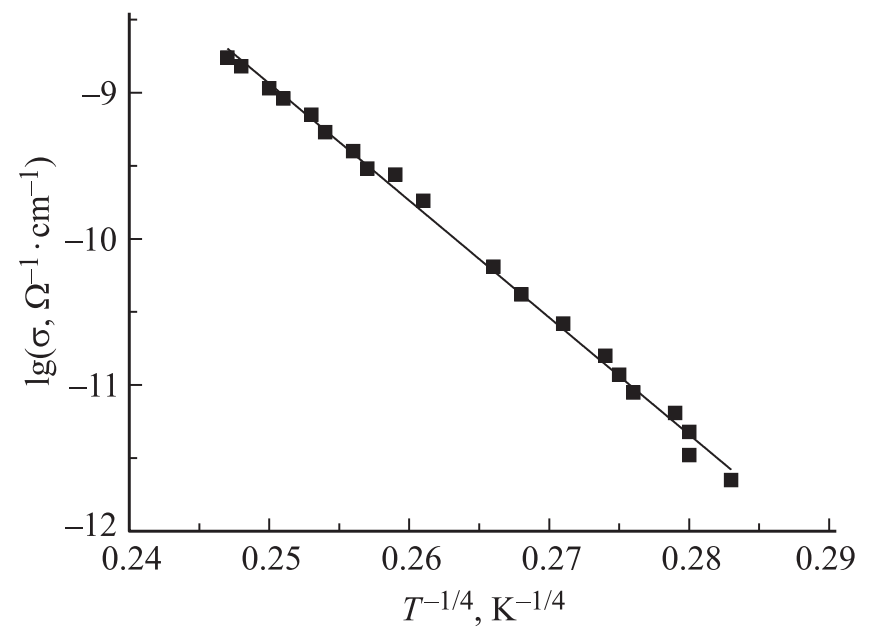

Рис. 1. Зависимость электропроводности поликристаллического образца $\mathrm{EuS}$ от $T^{-1 / 4}$.

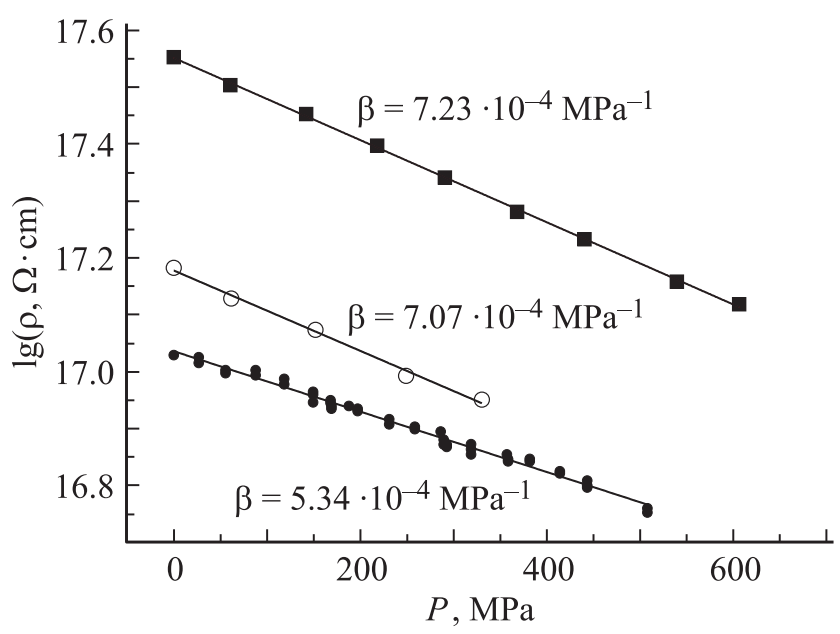

Рис. 2. Барические зависимости удельного электросопротивления поликристаллов EuS. Отрезки прямых - линейные аппроксимации барических зависимостей логарифма электросопротивления EuS, которым соответствуют расчетные значения барического коэффициента электросопротивления $\beta$ (указаны около прямых).

данные, полученные на поликристаллическом образце $\mathrm{EuS}$, показывают, что логарифм электропроводности линейно зависит от $T^{-1 / 4}$, что соответствует формуле (1) и подтверждает наличие прыжкового механизма электропроводности в интервале температур 150-260 K. При более высоких температурах наблюдается переход к проводимости с энергией активации, равной $0.4 \mathrm{eV}$.

Наличие прыжковой проводимости было проверено также с помощью другого, более оригинального метода, примененного нами ранее для тонких пленок $\mathrm{EuS}$ [4]. Метод основан на различном влиянии давления на зонную и прыжковую составляющие электропроводности. Действительно, прыжковая проводимость зависит от среднего расстояния $l$ между ионами, между которыми осуществляются прыжки электронов [8]. При не слишком высоких давлениях это расстояние меняется незначительно: $\Delta l / l \sim 10^{-3}$. Такой же порядок величины должно иметь и относительное изменение прыжковой составляющей электропроводности. Таким образом, прыжковая проводимость остается практически неизменной, являясь барически независимой добавкой к зонной проводимости, изменение которой под давлением на два порядка выше. Отсюда следует вывод, что чем меньше вклад в общую проводимость прыжковой проводимости, тем выше будет по модулю барический коэффициент электросопротивления $(\beta)$ материала. Прыжковая проводимость шунтирует зонную, уменьшая электросопротивление, а следовательно, и $\beta$.

Результаты исследований барических зависимостей электросопротивления моносульфида европия представлены на рис. 2. Анализ экспериментальных данных показывает, что исследуемые образцы $\mathrm{EuS}$, имеющие большее удельное электросопротивление при нормальных условиях, обладают более высоким по модулю барическим коэффициентом электросопротивления $\beta=\partial \ln R / \partial P$, что соответствует приведенным выше соображениям. Если учесть, что различные образцы $\mathrm{EuS}$, полученные из одного исходного поликристалла, могут отличаться друг от друга только количеством структурных дефектов, то указанный факт может быть объяснен наличием прыжковой проводимости по локализованным состояниям вблизи дна зоны проводимости, соответствующим ионам европия, находящимся вне регулярных узлов кристаллической решетки. Аналогичная ситуация наблюдалась нами на тонких поликристаллических пленках $\mathrm{EuS}$ в [4].

Уместность такой аналогии подтверждается следующим фактом. Для поликристаллических образцов, рассмотренных в настоящей работе, величина $\beta=-(5.34-7.23) \cdot 10^{-4} \mathrm{MPa}^{-1}$. Для тонких поликристаллических пленок, рассмотренных в [4], $\beta=-(1.35-1.59) \cdot 10^{-4} \mathrm{MPa}^{-1}$. Такое уменьшение $\beta$ у пленок связано с уменьшением размера областей когерентного рассеяния в материале пленки: для поликристаллов - 450-600 А, для пленок - 200-230 А. Согласно результатам, полученным для полного аналога $\mathrm{EuS}$ по структуре - SmS, эти величины определяют количество ионов европия, находящихся вне регулярных узлов кристаллической решетки: $1.2 \cdot 10^{21}$ и $3.5 \cdot 10^{21} \mathrm{~cm}^{-3}$ соответственно [9]. Последние определяют количество локализованных состояний, ответственных за прыжковую проводимость, ее доля в пленках значительно выше, а величина $\beta$ меньше.

Таким образом, можно считать, что в интервале температур 150-400 K в поликристаллах $\mathrm{EuS}$ основную роль в электропереносе играет прыжковая проводимость. Необходимым условием прыжковой проводимости является наличие свободных мест на донорах. Оно может быть обеспечено компенсацией полупроводника, т.е. присутствием некоторой концентрации неосновных примесей, например акцепторов, в электронном проводнике, которые захватывают часть электронов с доноров. 
В результате возникает такое же число пустых доноров (вакансий). B EuS наличие таких акцепторов может быть обусловлено, как и в $\mathrm{SmS}[10]$, наличием некоторого количества акцепторных дефектов.

Авторы благодарны Ю.В. Марковой за помощь в работе.

\section{Список литературы}

[1] А.В. Голубков, Е.В. Гончарова, В.П. Жузе, Г.М. Логинов, В.М. Сергеева, И.А. Смирнов. Физические свойства халькогенидов редкоземельных элементов. Наука, Л. (1973). $304 \mathrm{c}$.

[2] Y. Shapira, T.B. Reed. Phys. Rev. B 5, 4877 (1972).

[3] В.В. Щенников, Б.А. Гижевский, Н.М. Чеботаев, Л.А. Клинкова. ФММ 69, 82 (1990).

[4] В.В. Каминский, Н.Н. Степанов, М.М. Казанин, А.А. Молодых, С.М. Соловьев. ФТТ 55, 991 (2013).

[5] В.В. Каминский, М.М. Казанин, С.М. Соловьев, А.В. Голубков. ЖТФ 82, 6, 142 (2012).

[6] В.В. Каминский, Н.Н. Степанов, С.М. Соловьев. ФТВД 25, 74 (2015).

[7] Б.И. Шкловский, А.Л. Эфрос. УФН 117, 401 (1975).

[8] Н. Мотт, У. Туз. УФН 79, 691 (1963).

[9] Н.В. Шаренкова, В.В. Каминский, М.В. Романова, Л.Н. Васильев, Г.А. Каменская. ФТТ 50, 1158 (2008).

[10] А.В. Голубков, Е.В. Гончарова, В.А. Капустин, М.В. Романова, И.А. Смирнов. ФТТ 22, 3561 (1980). 